\title{
Change Management: Overcoming the Challenges of Introducing Self-Driven Learning
}

\author{
http://dx.doi.org/10.3991/ijep.v5i4.4945 \\ K.M. Berkling ${ }^{1}$ and A. Zundel ${ }^{2}$ \\ ${ }^{1}$ Cooperative State University, Karlsruhe, Germany \\ ${ }^{2}$ Inline Internet Online Dienste, GmbH, Karlsruhe
}

\begin{abstract}
This paper describes the process of designing a course for Software Engineering that promotes self-driven learning while taking into account student motivation, scaffolding and a constrained ecosystem at the Cooperative State University, Karlsruhe. The University has certain particularities that distinguish it from other Universities because students alternate quarters between study and work. Thus, students receive a salary during their three years towards earning a Bachelor Degree and attendance is mandatory. In cohorts of around 30 students a class spends an average day with at least 5 hours of mostly frontal lecture in the same classic classroom setup. Software Engineering takes up about 5 hours a week of in-class time in their second year of study and is the first course students have seen with a self-driven, blended learning format. The paper describes the process of designing a course for self-driven learning. It starts with a gamified approach that plunges the student directly into a new world of learning and ends with a scaffolded design that leads the students in a one-year-long process of "unschooling", leaving students less frustrated and more motivated, while still attaining a high level of achievement.
\end{abstract}

Index Terms-Blended Learning, Ecosystem of Learning, Education, Gamification, Peer Evaluation, Problem Based Learning, Software Engineering.

\section{INTRODUCTION}

In this paper, an approach to introducing self-driven blended learning is analyzed as it has changed over the course of three years. Each year around 90 students split into three classes are participants in the study by taking the mandatory Software Engineering course in their second year (out of three) during their Bachelor program at the Cooperative State University, Karlsruhe. The academic year is based on a Quarter system. Students spend alternating quarters studying or working, earning a salary throughout the year. Their attendance at University is mandatory and they study in cohorts. As students are required to remain within their cohort in order to graduate, failing a course may easily result in the failure of the entire Bachelor degree and preclude further study in that subject area in this University system. The combination of quarter system and a set six semesters towards a Bachelor degree results in students spending more than 5 hours a day and sometimes up to 25 hours per week in frontal lectures in the same classroom that has the classic wooden chairs, desks, blackboard and beamer. 15 minute breaks mornings and afternoons and a lunch break in the middle of the day round up the program. Evenings and weekends are spent with project work. From the teacher perspective, full-time lecturers can be teaching over 20 hours a week, including courses outside of their immediate expertise. Other lecturers teach on the side while working in industry. Both students and lecturers work under intense time and performance pressures.

Students have never before been responsible for their own learning beyond what is needed to perform well on an exam in a traditional setting. Neither in school nor at the University has self-regulated learning been explored. However, there are necessary reasons for changing the learning environment away from the frontal lecture from employers', students' and University points of view.

From the employer point of view, it is important to move students from a check-box based approach to obtaining good grades to a mastery based approach, which is more aligned with workplace demands. Whereas in school (including University), handing in something to be graded on a certain date may count as a completed task, industry work environment expects several passes through a piece of work until perfected. While one might think that behavior can be adapted based on environment, employers report that key reasons for not hiring students include their lack of transfer skills, lack of critical reflection on own performance and lack of soft-skills. Top desired skills apart from practical know-how are team skills and capability for self-driven learning. Industry expectations of Bachelors were met $63 \%$ of the time in 2011 . By 2015 this number had reduced to $47 \%$ ! Only $16 \%$ of those questioned would agree that the students have been well prepared for industry $[1,2] .80 \%$ of participants in the study are either working with the cooperative Bachelor model or planning to integrate it, thereby making the constrained ecosystem described here the new norm.

From the student point of view, reasons for changing the format of coursework are threefold: First, the number of hours spent listening to lectures can be decreased by letting students work independently towards pre-defined goals, thereby becoming more actively involved in the learning process. Second, with up to 25 weekly hours of frontal lecture, a self-determined format may be perceived as a nice change of pace. Finally, due to the noticeable difference in know-how between students and even between lecturer and student (working inside the fastmoving IT industry), there is an advantage to leaving space to learn from each other or proceed according to a personal profile gap between knowledge and desired skillset.

The University's reasons include knowledge of research results about positive learning outcomes when creating a more active and problem based learning environment [3, 
4] despite the fear of change [5]. Key reasons for change include the overwhelming variety of high-quality information sources that are available on the web. With the most current appearance of MOOCs (Massively Open Online Courses) from some of the top Universities in the US, standards for frontal lectures are set, including written transcripts of what was said, the ability to rewind and relisten to any lecture any time and communicating with an active global community. Increasingly, excellent information is available via Youtube and Internet outside of any systematic courses as students are relying less and less on books to acquire knowledge in the rapidly changing field of Information Technology. Even from one year of teaching to the next, there can be profound changes in technology that a set frontal lecture would not be able to cover in a practical manner.

The design of this Software Engineering course is an ongoing process that has taken three years so far and is not finalized. The study starts with a gamified course, in which students are abruptly confronted with the experience of self-driven learning. Even though the outcome of this course in 2012/13 resulted in a class of well-trained students in both theory and practical experience, the student perception reflected a stressful experience. We report on the survey that explores the discrepancy between teacher and student expectation. The goal of this exploratory study and corresponding survey is to understand student motivation in the example of a restrictive environment, where grades and efficiency are central to survival. A gap in research on this topic has been noted the literature [6].

Based on this outcome, the class in 2013/14 resulted in a scaffolded instruction method and a prescribed platform and timeline. Peer evaluation and forum entries were a necessary part of the teaching. Constrained by the technology, there was still a large room for improvement and a gap between motivation and teaching. Finally, the class of 2014/15 was set in an environment where motivation and setting were mostly aligned.

Section 2 will summarize the theoretical foundations of the didactic set-up for this approach. Section 3 discusses the student evaluation of the course, and describes the mismatch between design and reception. Section 4 and 5 motivates and describe the changes that the course has been submitted to over the subsequent two years. Section 6 concludes with final remarks on the experience and a general recipe for design.

\section{THEORETICAL FOUNDATION}

The software engineering course, originally a frontal lecture, was redesigned around motivators with content and platforms aligned as shown to be important [7]. This section discusses the theoretical foundation behind the motivators, the content design and platform requirements.

\section{A. Motivators}

Despite some controversy as to the exact definition of extrinsic and intrinsic motivators, we will distinguish internal drivers such as autonomy, purpose, and mastery from external drivers, a number of chosen mechanics from gamification that have been shown as effective in real world systems with academic research still forthcoming in this emerging field.

\section{B. Intrinsic Motivation}

According to positive psychology's theories about motivation [8-13], humans are motivated to work on cognitively difficult tasks when they are granted autonomy, purpose and mastery. Accordingly, the course was designed to grant students autonomy by allowing choice of speed and order for studying six out of nine topics of their choice (see 2.3) with enough time to obtain mastery. The purpose was given because the acquired knowledge would make students more powerful partners in project work for the coming quarter and because the material is immediately useful at their workplace as software engineers in training.

\section{Extrinsic Motivation}

Gamification is a controversial topic that has become ubiquitous in the business world since 2010 when the term was coined by the gamification community [14, 15]. Part of the idea behind gamification is to understand which mechanics keep gamers motivated to come back to play and apply those constructs to non-game environments with the goal of encouraging similar engagement. Since these have been shown to work [16-18], some typical game mechanics were incorporated into the classroom as listed in Table 1.

TABLE I.

THEORETICAL MOTIVATION / CLASSROOM REALIZATION: YeAR 1

\begin{tabular}{|c|c|c|}
\hline & Mechanics & Realization \\
\hline \multirow{5}{*}{ 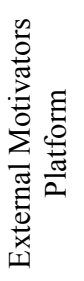 } & Aesthetics & Gamification platform \\
\hline & $\begin{array}{c}\text { Progress Bar } \\
\text { Overview }\end{array}$ & $\begin{array}{c}\text { Poster on wall } \\
\text { Gamification platform }\end{array}$ \\
\hline & Feedback & Moodle online quiz \\
\hline & Leaderboards & Email (anonymous) \\
\hline & $\begin{array}{l}\text { Points, Levels } \\
\text { Heroes }\end{array}$ & Gamification platform \\
\hline \multirow{4}{*}{ 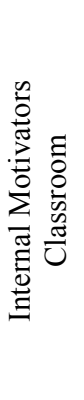 } & Autonomy & $\begin{array}{c}\text { Lecture on demand } \\
\text { Various paths though content } \\
\text { Personal timeline } \\
\text { Personal learning materials } \\
\text { and interaction } \\
\text { project, technology }\end{array}$ \\
\hline & Mastery & $\begin{array}{l}\text { Quiz until mastery } \\
\text { Bloom's Taxonomy }\end{array}$ \\
\hline & Purpose & $\begin{array}{l}2 \text { Semesters } \\
\text { Project based }\end{array}$ \\
\hline & Basic Needs & Teaching to the test \\
\hline
\end{tabular}

D. Content

Content is structured to support intrinsic motivation of autonomy as defined above for the purpose of this work. A choice of independent pathways organized into levels through the material is provided. Each of three paths consists of three topics of mastery divided into Bloom's cognitive levels.

\section{E. Topic Organization into Levels}

Topics covered in this Software Engineering course is structured into three pillars of three topics each: Software writing (Design Patterns, Metrics, Testing), Communication (Documentation, Estimation, Reverse Engineering) and Project Management (Processes, Configuration Management, Lifecycle Management) and culminates in project based experience. The current version of the topic 
separates the theoretical parts into the first Quarter and the project part into the second Quarter, with students spending the intermittent Quarter in their respective work places. This separation is designed to give students enough time to learn all aspects of Software Engineering before applying the collective know-how in a project. Additionally, tuned into the subtopics, they are able to inspect how these topics are treated in their workplace during their practical phase, thereby integrating industry know-how into the classroom.

\section{F. Towards High-Level Thinking with Bloom's Taxonomy}

Bloom's taxonomy classifies educational goals into a hierarchical system in the cognitive domain and builds towards higher level thinking skills and has been used effectively in Computer Science in the past [19, 20]. An example is depicted in Figure 1 for the topic of Software Testing. At the knowledge level, students receive a theoretical lecture on demand. Here, terminology, facts, principles and theories are presented. For the example of testing the lecture explains what the different types of software tests are, when they are performed and what they cover.

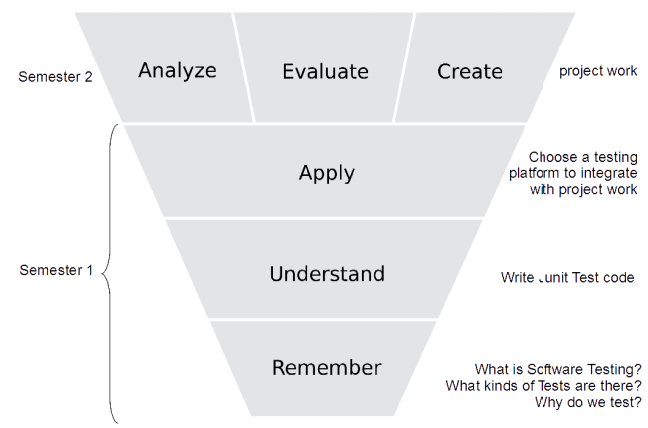

Figure 1. Bloom's Taxonomy as applied to one of the learning areas in Software Engineering

Understanding the facts is encouraged by asking students to then implement several unit tests for a given suggested code or a code of their own choice. They are then asked to choose a testing framework for later use in their projects to prepare for the next semester. For example, how can tests be automated and tied in with the lifecycle management. Analysis, Evaluation and Creation of further tests is then left to the actual project based experience in the next Quarter/Semester in a larger scale testing environment.

\section{G. Blended Learning}

Learning platform(s) are integrated into the classroom in order to create a blended learning environment to match motivators [21-23] with the known shortcoming of not living up to professional graphic interfaces that people are used to these days [24]. Table I lists the connections that were implemented in this case to align motivators with elements of blended learning environment.

\section{H. E-Platforms}

Lecture slides and learning objectives for each of the nine topics to be studied where provided on Moodle and supplemented with links to external information and tools. Online quizzes provided a $24 \times 7$ platform for submitting work to be checked manually by the lecturer to provide more or less immediate and personal feedback. In addition, a separate gamification platform apart from Moodle supplied explicit task lists, levels, points, a progress bar and an overview over class progress that was also available in paper form on the wall.

\section{Human Interaction}

With 5 hours of in-class time per week and mandatory attendance, this time is used for teamwork among students and choosing frontal lectures on any of the nine topics on demand as the student progresses through the topics (levels). Theoretically, the student has the opportunity to pick up to 9 lectures in any order over the course of 11 weeks duration of the quarter and work through related problem sets and quizzes with feedback from instructor with no restriction on collaboration. Only six topics were required for the final exam that covers only the "remember" level of Bloom's taxonomy but would be facilitated by understanding the topics more thoroughly after completing all three of Bloom's cognitive levels per topic. The next section will describe the experience from the teacher point of view.

\section{QuAntitative ANALYSIS OF STUDENT SURVEY}

An exploratory survey was conducted to find out what students expect from a good class and how they are motivated in order to receive feedback on the class set up and how well it matches their motivators. The survey was not mandatory and 59 students chose to anticipate in anonymous manner during weeks 8 and 9 out of a total of 11 . These responses form the basis of the reported analysis. To get a rough idea about how well the course was received, students were asked to give it a grade. The grading for Software Engineering (open format) is about equal with a clear tendency toward preferring the frontal, known style. The student survey answers were useful in finding out why the hypothesis that open format is preferable was naïve.

\section{A. Student Profiles.}

It is of interest to study how students' profiles differ according to how they like each format (frontal vs. Software Engineering). Based on the grades the students gave, they were grouped into "Dislike", giving a bad grade $(1<=$ grade $<3)$ and "Like", giving a good grade $(3<$ grade $<=$ $6)$ for each format. The resulting number of students in each category is shown in Table II:

TABLE II.

SUBSET OF STUDENTS WITH STRONG DiS/LIKES

\begin{tabular}{|l|c|c|}
\hline \# of students & $\begin{array}{c}\text { Like } \\
(\text { grade }<\text { 3) }\end{array}$ & $\begin{array}{c}\text { Dislike } \\
(\text { grade }>\text { 3) }\end{array}$ \\
\hline Software Engineering & 21 & 19 \\
\hline Average Frontal Lecture & 20 & 9 \\
\hline
\end{tabular}

\section{B. Perception of Format}

Two hypotheses were that students grow to like the format after getting used to it and that prior knowledge would automatically lead to a higher acceptance of the course format.

As expected, students who like the new format noted an improvement of the format over time. However, students who dislike the format alarmingly worsened their opinion 
over time indicating a lack of necessary scaffolding. Figure 2 shows that opinion on course format does not depend on prior knowledge of material.

\section{Students' Expectation of Lecturer}

In order to understand the acceptance of the new format, the survey also gathered information on desired characteristics of a lecturer that are perceived as desirable. The hypothesis was that a teacher should know how to teach and have expertise both in theory and work experience. Yet, as shown in Figure 3, students overwhelmingly answered that it is important to see problems, solutions and obtain a transcript of the lecture to study from (as opposed to a book that covers more material than necessary, according to student feedback). This seems to point towards students that are training to the test. Mostly the same is true for all students regardless of preferred course format.

\section{Student Motivators}

Since one of the key design elements of the new format builds on motivating students according to research-based ideas on what motivates humans in general, it is of interest to poll students on their motivators in alignment with the elements in Table I above. Under the elements of purpose, mastery, autonomy, and extrinsic (grade) / intrinsic (content) motivation, the questionnaire seeks to explore which elements are motivating for students.

Added categories include challenges and urgency from game mechanics. The original hypothesis that we wanted to explore was whether students can be grouped by motivators that can then be catered to in different teaching styles and with different mechanics.

Instead, there was an overwhelming response across all students regarding purpose and path as the main motivators (Fig. 4). After asking students, this is to be interpreted within the framework of taking an exam and obtaining a high grade. The clear path refers to receiving material from the teacher that prepares for the exam with the purpose of knowing this material to obtain a good/passing grade. The key is to fulfill the basic needs of staying in the program. It is probably correct to summarize the data to say that the lecturer and teaching style is less important than finding the correct information for the exam.

\section{E. Qualitative Analysis of Student Feedback}

General student qualitative feedback, especially for those that struggled with the new format reflected three major areas: 1. the importance of knowing how to obtain a good grade, 2. the difficulty of on-boarding in this new learning style, 3 . the lack of supporting material even after buy-in to the new format.

\section{F. Open Questions vs. Clear Answers}

The importance of the exam and the grade and as a result the desire for clear "structure" - meaning that the lectures should be very exact in preparing the student for the exam by clearly covering necessary material, sample questions and corresponding answers that are known to be correct is clearly the equivalent of the basic need that should be fulfilled given the students" "ecosystem" at the University. This student goal is diagonally opposed to the inability to memorize the correct answer to a question like: "List and weigh important criteria when selecting a supporting tool for Lifecycle Management. Then compare two tools of your choice and argue your final choice based

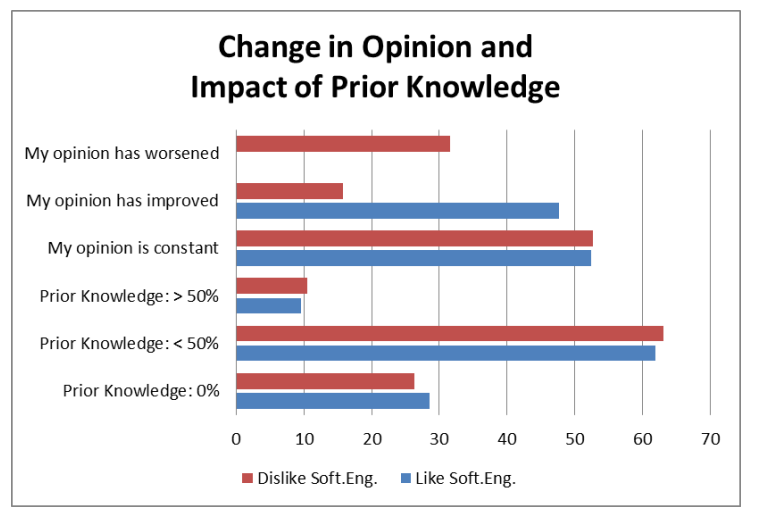

Figure 2. Impact of prior knowledge on acceptance of course format and change in opinion over time for subsets of students with strong likes and dislikes

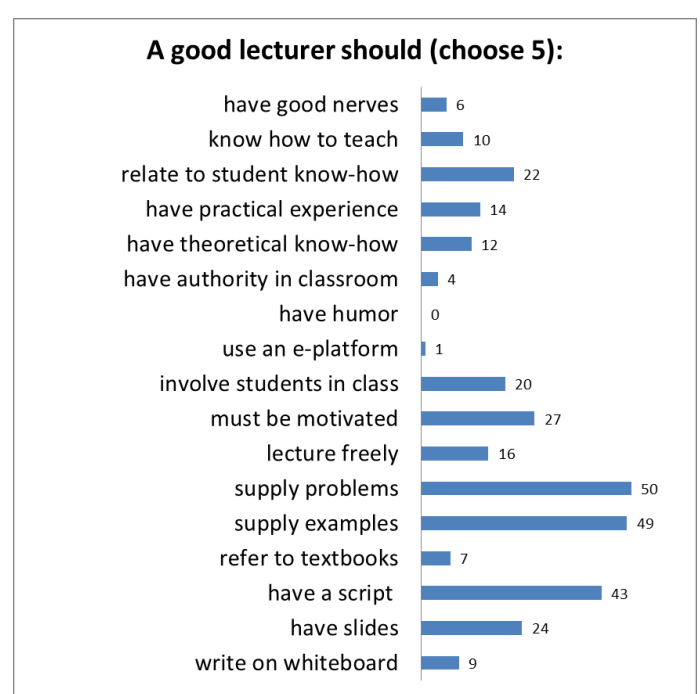

Figure 3. Number of students who choose specific lecturer characteristic

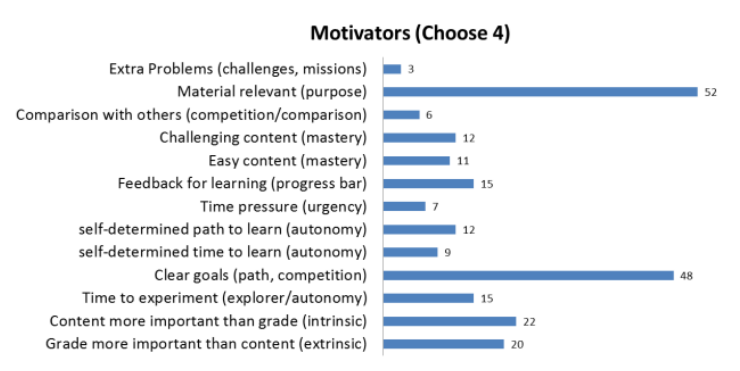

Figure 4. Number of students who voted motivator as important (choosing up to four motivators)

on your chosen criteria and assumptions." While this may be a real-life question as it would be posed in the workplace, it is not a "good" exam question (like "What does UML stand for?") as it does not have a single correct response that could potentially be memorized. A good answer would reflect how much time a student has spent looking at what Lifecycle Management is (information given in a lecture), what kinds of processes it can support (lecture) finally what types of tools and capabilities are available on the market and which features distinguish these (research on the web with provided links to start). The student has to be able to analytically formulate criteria based on assumptions that are important to a project 
and with those in mind compare a number of tools. This requires analytical thinking and transfer of know-how to unknown situations, an important skill with constantly changing tools in information technology. There is no correct answer and assumptions have to be stated as part of the answer to the question. Yet, results from this work show a clear need for facilitating the move towards answering these kinds of questions.

\section{G. On-boarding}

Key take-home message from feedback of all students is that the on-boarding process, the steps from frontal lecture to free learning has to be gradual and guided. Students had problems with

- scheduling their own work

- asking for lectures on demand

- using the platform to their advantage (taking quizzes regularly, improving answers upon feedback, contacting expert students for help)

- leveraging in-class time (collaboration, lectures)

- understanding that a question has more than one correct answer

Feedback clarified the need for providing more scaffolding at the beginning of the class and removing these at rates depending on the individual student. One of the questions on the questionnaire asked students how they could have taken better advantage of the new format of learning. It is remarkable to note that only around five students were able to reflect on their own ability to cope with the new format. The importance of acknowledging such difficulties and the need to "[...] intentionally articulate[...] and foster[...] self-reflection and awareness of processes important to learning such as self-efficacy" ([6] p. 1727) has been documented in the literature.

The study showed clearly that the semantics behind motivators such as autonomy, purpose and mastery are defined differently for students. Mastery relates to memorizing material for an exam in such a way as to receive a good grade. Autonomy means that a student is able to not participate during class time and choose their own time for learning. Purpose is to pass the class to obtain a Bachelor and a job. For a more detailed analysis of this survey see [25].

\section{YEAR 2 - 1 PlATFORM FOR EVERYTHING}

The second year is characterized by merging theory and project work as well as scaffolding [26] and unifying the platform. A detailed analysis of the failure of the first year in motivating students and the subsequent redesign are given in $[27,28]$. The lecturer provides set deadlines for specific homework and a single platform that has everything. This year students were not so overwhelmed by the teaching style. Instead the key problem was the platform that offers everything too quickly and not with high enough quality for students who are used to the smooth interface of Facebook and co.

\section{A. Intrinsic Motivation}

Autonomy was granted for technology and project idea. There was no autonomy with respect to order and deadline of homework. The platform was prescribed. Forum use and peer review were requirements. Theory and project were mixed (compared to theory followed by practical semester in the preceding year). Mastery was maintained by allowing multiple hand-ins for grading. Online quizzes were maintained but discussed in class rather than corrected and returned by teacher. The exam was multiple-choice and evaluated automatically. Students were allowed to take the exam twice. Between exams, students were allowed to discuss the answers or ask questions. Students still gamified that system by trying to memorize answers, first as $1 b, 2 c, \ldots$ and later on with the first word of the answer when they noticed that answers were sorted in random order. The point however, was not the grade of the second quiz but the discussion between the two exams in class, which contributed to understanding the material, according to teacher observation and informal polling of student opinion after each in-class quiz.

\section{B. Extrinsic Motivation}

Extrinsic motivation is addressed through continuous grading. The current cumulative grade was always visible to each student at all times. Each week quiz and homework were graded and thus students had control over their grade. The quiz grade was automated and homework was graded through peer review. Peer reviews were given on platform, private and anonymous. Table III summarizes how these motivators are realized in the classroom.

\section{Content}

Content is given by weekly homework with a given path and speed. Theory is now mixed with project so that Bloom's taxonomy does not appear separated to the student but integrated directly into the project work. Each of the three pillars of the Software Engineering course is covered as the project progresses. The week lecture pertains directly to the homework that is to be implemented within each team's project. In addition to the team grade for the project, tech-talks are introduced. Each student picks a topic of their personal interest in software engineering and presents it to the class over the course of the 24 weeks of the 2-semester course. This helps to connect a student's industry know-how with the class content.

TABLE III.

THEORETICAL MOTIVATION / CLASSROOM REALIZATION: YeAR 2

\begin{tabular}{|c|c|c|}
\hline & Mechanics & Realization \\
\hline \multirow{5}{*}{ 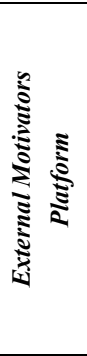 } & Aesthetics & - \\
\hline & $\begin{array}{l}\text { Progress Bar } \\
\text { Overview }\end{array}$ & $\begin{array}{l}\text { Continuous personal view of } \\
\text { grades on platform }\end{array}$ \\
\hline & Feedback & $\begin{array}{l}\text { quiz with automated grading, } \\
\text { homework through peer } \\
\text { reviews }\end{array}$ \\
\hline & Leaderboards & - \\
\hline & $\begin{array}{l}\text { Points, Levels } \\
\text { Heroes }\end{array}$ & $\begin{array}{l}\text { continuous grading } \\
\text { not public }\end{array}$ \\
\hline \multirow{4}{*}{ 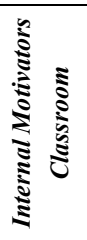 } & Autonomy & project, technology \\
\hline & Mastery & $\begin{array}{l}2 \text { theory quizzes with discus- } \\
\text { sion }\end{array}$ \\
\hline & Purpose & control over grade \\
\hline & Basic Needs & $\begin{array}{l}\text { regular testing and homework } \\
\text { to grant multiple lives }\end{array}$ \\
\hline
\end{tabular}

\section{E-Platforms and Blended LearningAspects}

Lectures were given to the entire class in a prescribed order determined by the lecturer. All other work took 
place on the platform, including grades, quizzes, homework, forum entries, peer reviews for homework.

\section{E. Human Interaction}

With 5 hours of in-class time per week and mandatory attendance, this time is used for attending the lecture, taking the quiz pertaining to last week's lecture, peerreviews, teamwork among students and tech-talk given by students for their personal component of the grade.

\section{F. Conclusions}

While this course left students more content due to the high level of scaffolding, a major drawback was the constraint of a single platform that was overwhelming to some learner types. Below is a short summary of findings; more details are given in [31].

For the purpose of this work, Grasha's definition of a learning style as somebody's preferred way of learning $[29,30]$ is sufficient because they are used as stereotypes for a first approximation in an iterative approach to understanding subgroups of students' usage of platform functionality. According to the Grasha-Riechmann Student Learning Style Scales, there are six styles that can be differentiated amongst learners as given in Table IV. These profiles represent theoretical stereotypes; based on their description, characteristic platform usage profiles were defined. The usefulness of such profiles was then validated as they prove helpful as an intermediary step to define homogeneous subgroups of user profiles using the eplatform in a particular manner.

TABLE IV.

LEARNER TYPES

\begin{tabular}{|l|}
\hline $\begin{array}{l}\text { The participant learner is very interested in the course content and } \\
\text { asks questions. }\end{array}$ \\
\hline $\begin{array}{l}\text { The avoidant learner works as little as possible or only shortly before } \\
\text { a dead-line. }\end{array}$ \\
\hline $\begin{array}{l}\text { The independent learner works on his/her own and rarely asks for } \\
\text { help. }\end{array}$ \\
\hline The dependent learner needs lots of support and detailed instruction. \\
\hline The collaborative learner prefers working in a team. \\
\hline $\begin{array}{l}\text { The competitive learner wants to do better than other course partici- } \\
\text { pants. }\end{array}$ \\
\hline
\end{tabular}

Using these theoretical definitions an exaggerated eplatform usage pattern for each can be defined. Usage patterns relate to the various aspects of any platform as listed here in broad categories:

- Content dimension: self-made, peer-made, professionally made, static, dynamic, ...

- Time dimension: synchronous (classic course), asynchronous (on demand/on progress), mixed

- Grading dimension: grades based on: forum entries, likes, homeworks, peer-grading, ...

- Leaderboards

- Social dimension: teams or working alone, ...

- "Living" spaces (scope): Global (Forum), Team (Journal, blog, ..), Personal (Journal, Blog....), Private

Patterns of usage become evident according to the degree to which a student matches a combination of the stereotypes. If common manifestations exist, then the student body can be described in such terms as subgroups.
In [31] we show how students can be categorized accordingly. The result shows a diverse group of students can be defined based on the way the e-Platform is used. Figure 5 depicts the fragmented, yet categorized distribution of the student body. From this study, it seems clear why providing a single non-adaptive platform for diverging usage patterns limits the user experience and motivation.

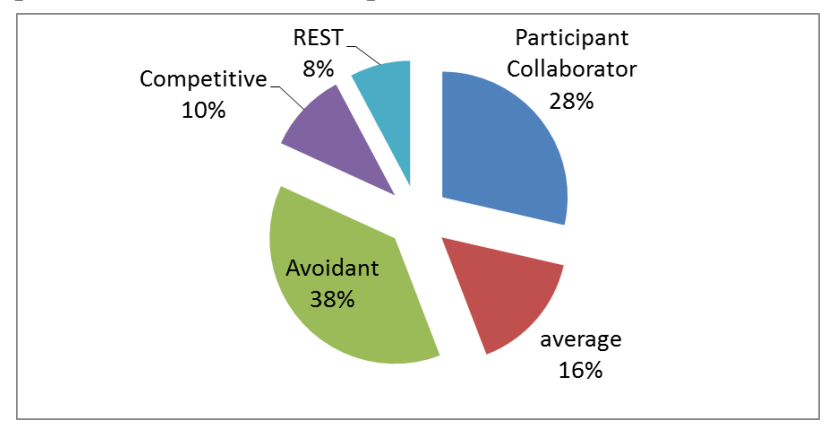

Figure 5. Fragmented student body

\section{YEAR 3 - OPEN PlATFORM}

The third year is characterized by adapting to various learning styles through opening another dimension of freedom. No adaptive e-Platform for teaching was available at the time of teaching this course. Yet, the necessity was clearly shown as a result of the previous year's offering. Therefore, instead of prescribing a learning platform for exchange of information, students chose their own "living"-spaces. With this step, peer reviews became public and no longer anonymous. Grading of peer reviews no longer depended on the content of the review but on the fact that the review was useful to the other team. These changes made a significant difference in student motivation. It is important to note that the resulting higher motivation was independent of learner type [33]. Table V shows the new realization of the motivators.

TABLE V.

THEORETICAL MotiVATION / ClassRoom REALIZATION: YeAR 3

\begin{tabular}{|c|c|c|}
\hline & Mechanics & Realization \\
\hline \multirow{5}{*}{ 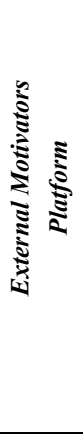 } & Aesthetics & $\begin{array}{l}\text { Teams crafted blogs that were very } \\
\text { well done }\end{array}$ \\
\hline & $\begin{array}{l}\text { Progress Bar } \\
\text { Overview }\end{array}$ & $\begin{array}{l}\text { Weekly points for peer reviews } \\
\text { with associated points ( } 30 \% \text { of } \\
\text { total grade) }\end{array}$ \\
\hline & Feedback & Weekly peer reviews \\
\hline & Leaderboards & $\begin{array}{l}\text { Indirectly via showing off beauti- } \\
\text { fully done blogs }\end{array}$ \\
\hline & $\begin{array}{l}\text { Points, Levels } \\
\text { Heroes }\end{array}$ & $\begin{array}{l}\text { Blogs, super projects, well-done } \\
\text { homework, good peer reviews }\end{array}$ \\
\hline \multirow{4}{*}{ 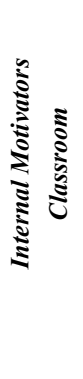 } & Autonomy & Platform, project, technology \\
\hline & Mastery & $\begin{array}{l}\text { Integration of theory and projec- } \\
\text { twork (Tagg), peer-reviews to } \\
\text { attain best possible hand-in for } \\
\text { grading by teacher }\end{array}$ \\
\hline & Purpose & Finish the project with high grade \\
\hline & Basic Needs & $\begin{array}{l}\text { Clear grading structure und multi- } \\
\text { ple "lives", ie. Control grade with } \\
\text { multiple hand-in }\end{array}$ \\
\hline
\end{tabular}




\section{A. Intrinsic Motivation}

Autonomy was granted by allowing choice of project, technology, personal tech-talk topic, and "living" space. Students designed their own blogs. Peer reviews were given on the team blogs and signed by the authors. Mastery was lived on the blogs. There were a number of peer reviews that resulted in conversations and several rounds until the peer reviewers were happy with the homework. The purpose is still to obtain a good grade for the final hand-in that consisted of the collection of peer-reviewed homework. Scaffolding was provided by setting dates for homework submission and peer reviews. Handing in peer reviews, receiving a peer review and giving feedback to their usefulness resulted in points toward the final grade.

\section{B. Extrinsic Motivation}

Extrinsic motivation was not only to reach the final grade but also to have public recognition of a well-done blog. The following blog entries in Table VI exemplify the type of interaction that has taken place during the homework and peer review process. Noticeable are the high quality, the politeness, and the reaction of the team to the feedback, taking the time to check multiple times and finally referring to another blog for a good example of the homework. In this particular homework, a graph plotting time vs. Function Point estimation for use cases was required. Most blog entries approximate some of these qualities to varying degrees. Note also that English is a foreign language for these students.

TABLE VI.

A PEER REVIEW ON A BLOG

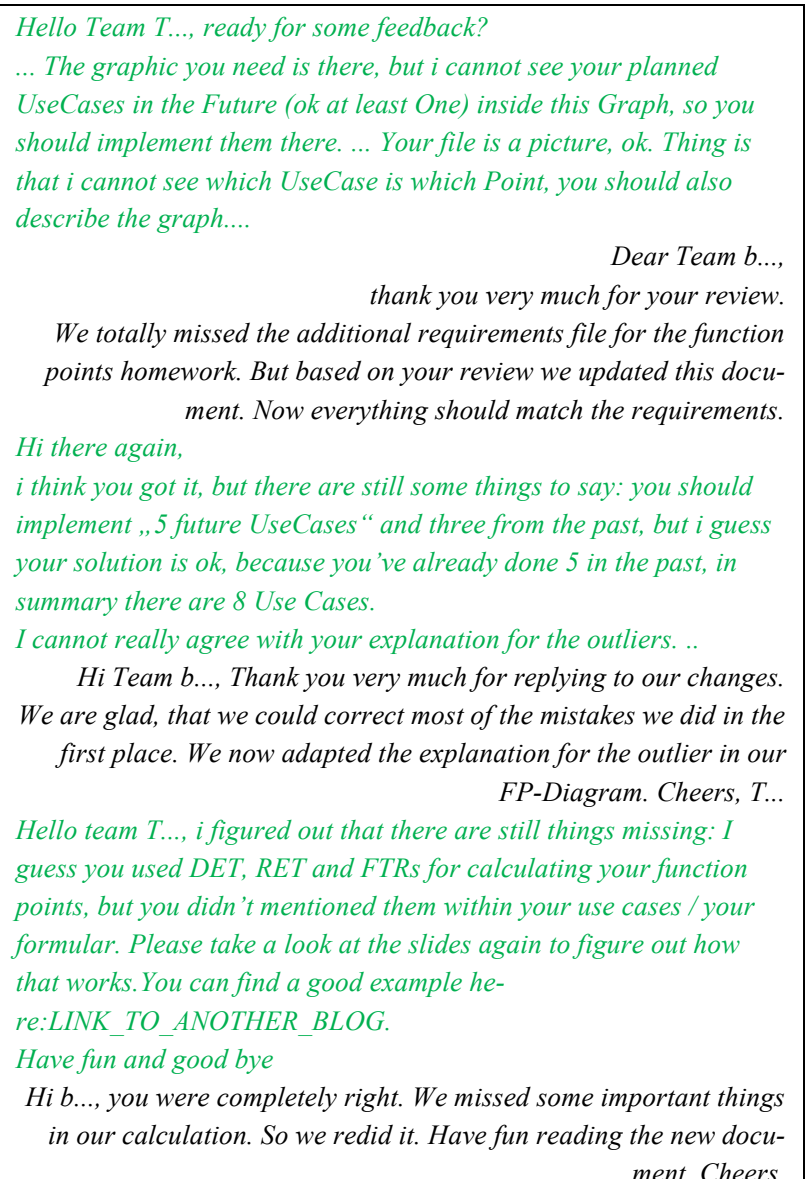
ment. Cheers.

\section{Content}

Content is given as in year 2 .

\section{E-Platforms and Blended LearningAspects}

Electronic quizzes were skipped this year for the sake of intensifying peer reviews. The only central platform was Moodle as a static place to upload lecture slides and information about deadlines as well as links to blogs with information about needed peer reviews. Grades were not visible on a platform due to the independent setup. Most students chose either WordPress or installed a blog on their own server.

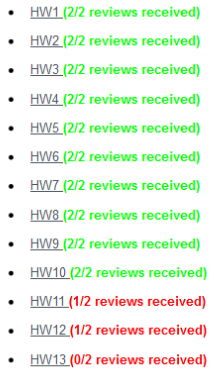

Figure 6. Keeping track of peer reviews

\section{E. Human Interaction}

There is a key difference with respect to Year 2 in this area. Every week, students had to show their received peer review and their given review in order to obtain points. The lecturer read the reviews and ensured that they covered the important aspects. In this way, the lecturer has an indirection towards checking the homework each week. With 90 students this is a realistic way of keeping up to date with their work. In addition, homework was presented in front of class by a subset of teams each week in order to make sure there were no misunderstandings of the material.

\section{F. Conclusions}

Students gave positive feedback to the course as shown in Figure 7. One major improvement over the last three years has been the acceptance of the teaching format across various learner types. Whereas in the first year, the survey has shown that there is a clear polarization between the group of students who do not enjoy open teaching style and those who like it, further work has shown that scaffolding can reach more learner types without alienating the high achieving group. The details of this evaluation can be found in [33].

\section{Grading}

$\square 1$ (best) $\square 2 \square 3 \square 4 \square 5 \square 6$ (worst)

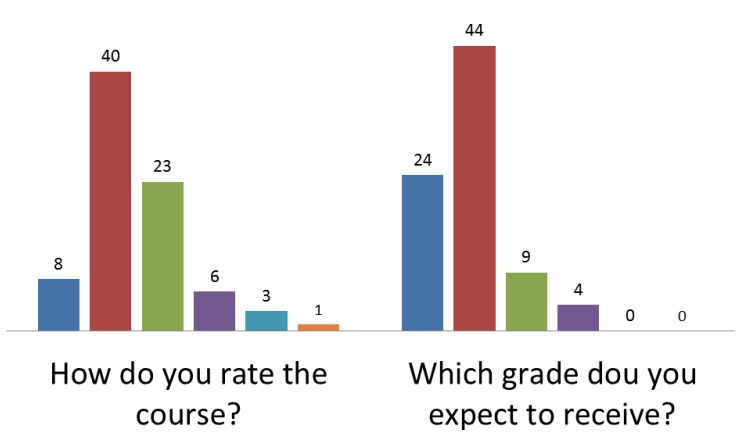

Figure 7. Rating the course and expected grade. 


\section{CONCLUSIONS AND FUTURE WORK}

A software engineering course was redesigned over the course of several years in order to support self-guided learning, a goal that is driven both by industry and university and indirectly by students, who perceive the traditional way of learning as unsatisfactory. After a radical first version of the redesigned course that catapulted students from regular frontal lecture directly into a self-learning environment, student discomfort was so strong that it required further modification. After two more revisions the current version of the course is able to teach the material, lead students towards self-guided learning and maintain student motivation across a variety of learner types.

Given the positive motivation for the students, their performance is equally important. $75 \%$ of students received a grade higher than a 2 (equivalent to Anglophone B). 80\% of students are within the top three tiers of feeling confident about the content in the nine topics covering software writing, communication and project management as described above. According to the same self-evaluation questionnaire taken voluntarily by a subgroup of students, the group in 2015 (70 students) feels more confident than the group in 2013 (56 students) as shown in Figure 8.

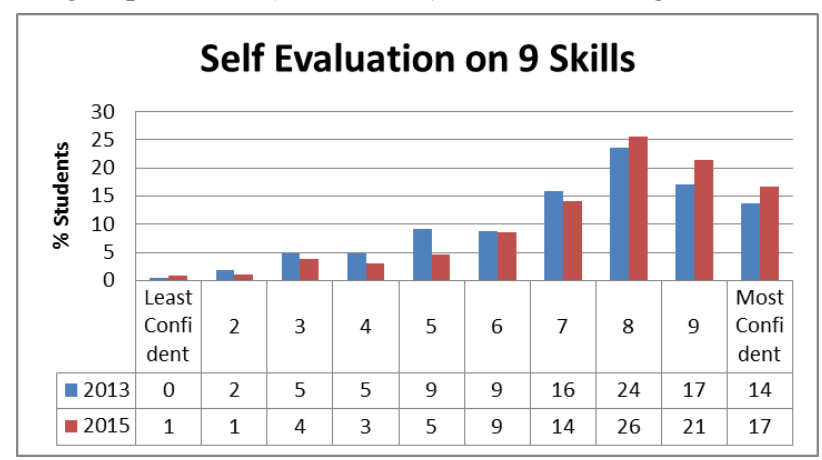

Figure 8. Self-evaluation of 9 skills on 10-point scale for 2013 and 2015, resulting in 503 and 627 answers respectively.

The following changes to any frontal lecture are a recommended recipe based on this experience: It is necessary to meet the basic needs of the students to make the path to good grades clear [32]. The teacher needs to decide beforehand, where to create freedom and in which places to scaffold. Scaffolding in the sense of the work presented here meant to enforce the creation of habits towards selfguided learning through setting deadlines and rewarding work with points that count towards a grade. This was shown to be the most important key support based on the first survey of student motivation, when students had trouble with scheduling their own work and using the platform to their advantage.

At the same time, it is important not to let platform technology stand in the way of productivity. The negative evaluation this course receives today pertains to the amount of work the course necessitates. This, however, is not likely to change in future versions.

\section{ACKNOWLEDGMENT}

The authors thank the students for providing constructive feedback to the teaching methods and most of all for the creative and rewarding projects that have come out of this course that make it a joy to teach.

\section{REFERENCES}

[1] K. Heidenreich, Erwartungen der Wirtschaft an Hochschulabsolventen.

[2] O. Heikaus and J. Flasdick, Kompetent und praxisnah Erwartungen der Wirtschaft an Hochschulabsolventen.

[3] D. R. Garrison and H. Kanuka, "Blended learning: Uncovering its transformative potential in higher education," The internet and higher education, vol. 7, no. 2, pp. 95-105, 2004. http://dx.doi.org/10.1016/j.iheduc.2004.02.001

[4] S. Goel and N. Sharda, "What Do Engineers Want? Examining Engineering Education through Bloom's Taxonomy," Online Submission, 2004

[5] S. R. Hall, I. Waitz, D. R. Brodeu, D. H. Soderholm, and R. Nasr, "Adoption of active learning in a lecture-based engineering class," in Frontiers in Education, 2002. FIE 2002. 32nd Annual, 2002, pp. T2A-9.

[6] P. Shea and T. Bidjerano, "Learning presence: Towards a theory of self-efficacy, self-regulation, and the development of a communities of inquiry in online and blended learning environments," Computers \& Education, vol. 55, no. 4, pp. 1721-1731, 2010. http://dx.doi.org/10.1016/j.compedu.2010.07.017

[7] M. Derntl and R. Motschnig-Pitrik, "The role of structure, patterns, and people in blended learning," The internet and higher education, vol. 8, no. 2, pp. 111-130, 2005. http://dx.doi.org/10.1016/j.iheduc.2005.03.002

[8] D. H. Pink and Summaries, Soundview Executive Book, The surprising truth about what motivates us: Soundview Executive Book Summaries, 2010.

[9] E. L. Deci and R. M. Ryan, "Motivation, personality, and development within embedded social contexts: An overview of selfdetermination theory," The Oxford handbook of human motivation, pp. 85-107, 2012.

[10] C. S. Rigby, E. L. Deci, B. C. Patrick, and R. M. Ryan, "Beyond the intrinsic-extrinsic dichotomy: Self-determination in motivation and learning," Motivation and Emotion, vol. 16, no. 3, pp. 165185, 1992. http://dx.doi.org/10.1007/BF00991650

[11] M. E. P. Seligman and M. Csikszentmihalyi, Positive psychology: An introduction: American Psychological Association, 2000.

[12] G. Kearsley, Online education: Learning and teaching in cyberspace. Belmont: Wadsworth Thomson Learning, 2000.

[13] M. Gagné and E. L. Deci, "Self-determination theory and work motivation," Journal of Organizational behavior, vol. 26, no. 4, pp. 331-362, 2005. http://dx.doi.org/10.1002/job.322

[14] J. McGonigal, Reality is broken: Why games make us better and how they can change the world: Penguin, 2011.

[15] G. Zichermann and J. Linder, Game-based marketing: Inspire customer loyalty through rewards, challenges, and contests. Available:

http://site.ebrary.com/lib/academiccompletetitles/home.action.

[16] M. R. Lepper, J. Henderlong, and I. Gingras, "Understanding the effects of extrinsic rewards on intrinsic motivation-Uses and abuses of meta-anlysis: Comment on Deci, Koestner, and Ryan (1999)," 1999.

[17] J. B. Rebitzer and L. J. Taylor, "Extrinsic rewards and intrinsic motives: Standard and behavioral approaches to agency and labor markets," Handbook of labor economics, vol. 4, pp. 701-772, 2011. http://dx.doi.org/10.1016/S0169-7218(11)04114-1

[18] T. Charles, D. Bustard, and M. Black, "Experiences of promoting student engagement through game-enhanced learning," in Serious games and edutainment applications: Springer, 2011, pp. 425445. http://dx.doi.org/10.1007/978-1-4471-2161-9_21

[19] D. R. Krathwohl, "A revision of Bloom's taxonomy: An overview," Theory into practice, vol. 41, no. 4, pp. 212-218, 2002. http://dx.doi.org/10.1207/s15430421tip4104_2

[20] E. Thompson, A. Luxton-Reilly, J. L. Whalley, M. Hu, and P. Robbins, "Bloom's taxonomy for CS assessment," in Proceedings of the tenth conference on Australasian computing educationVolume 78, 2008, pp. 155-161.

[21] T. A. Bekele, "Motivation and satisfaction in internet-supported learning environments: A review," Journal of Educational Technology \& Society, vol. 13, no. 2, pp. 116-127, 2010. 
PAPER

Change Management: Overcoming the Challenges of INTROducing SELF-Driven LeARning

[22] C. R. Graham, "Blended learning systems," CJ Bonk \& CR Graham, The handbook of blended learning: Global perspectives, local designs. Pfeiffer, 2006.

[23] S. Mohammad and M. A. Job, "Confidence-MotivationSatisfaction-Performance(CMSP) Analysis of Blended Learning System in the Arab Open University Bahrain," International Journal of Information Technology and Business Management, vol. 3, no. 1, 2012.

[24] A. Schober and L. Keller, "Impact factors for learner motivation in Blended Learning environments," International Journal of Emerging Technologies in Learning (iJET), vol. 7, no. 2012, 2012.

[25] K. Berkling and A. Zundel, "Understanding the Challenges of Introducing Self-driven Blended Learning in a Restrictive Ecosystem-Step 1 for Change Management: Understanding Student Motivation," in 5th International Conference on Computer Supported Education (CSEDU), 2013, pp. 311-320.

[26] J. Tagg, The learning paradigm college: Anker Publishing Company Bolton, MA, USA, 2003.

[27] C. Thomas and K. Berkling, "Redesign of a gamified Software Engineering course," in Interactive Collaborative Learning (ICL), 2013 International Conference on, 2013, pp. 778-786. http://dx.doi.org/10.1109/icl.2013.6644707

[28] K. Berkling and C. Thomas, "Gamification of a Software Engineering Course-and a detailed analysis of the factors that lead to it's failure. Submitted to ICL 2013," in Interactive Collaborative Learning (ICL), 2013 International Conference on, 2013, pp. 525530.

[29] A. F. Grasha, "A matter of style: The teacher as expert, formal authority, personal model, facilitator, and delegator," College teaching, vol. 42, no. 4, pp. 142-149, 1994. http://dx.doi.org/10.1080/87567555.1994.9926845
[30] B. S. Fuhrmann and A. F. Grasha, A practical handbook for college teachers. Boston: Little Brown \& Co, 1983.

[31] K. Berkling and C. Thomas, "Looking for Usage Patterns in eLearning Platforms - a step towards adaptive environments," in 6th International Conference on Computer Supported Education (CSEDU), 2014.

[32] A. H. Maslow, "A theory of human motivation," Psychological review, vol. 50, no. 4, p. 370, 1943. http://dx.doi.org/10.1037/ h0054346

[33] K. Berkling, "Connecting Peer Reviews with Student Motivation Onboarding, Motivation and Blended Learning," in 7th International Conference on Computer Supported Education (CSEDU), 2015. http://dx.doi.org/10.5220/0005410200240033

\section{AUTHORS}

Prof. K. M. Berkling, PhD is a professor of Computer Science at the Cooperative State University in Karlsruhe, Germany. She has been teaching Software Engineering since 2004 and is Senior member of IEEE; Berkling@dhbw-karlsruhe.de.

Dr. A. Zundel, has been teaching Computer Science as Professor at the Polytechnic University of Puerto Rico, the University of Virgin Islands. He is currently an adjunct lecturer at the Cooperative State University, Karlsruhe. He is the CEO of his own company since 1996 delivering ITservices; Zundel@inline.de.

This article is an extended and modified version of a paper presented at the 5th International Conference on Computer Supported Education (CSEDU 2015), 23-25 May 2015, Lisbon, Portugal. Submitted $07 \mathrm{Au}-$ gust 2015. Published as resubmitted by the authors 10 October 2015. 